\title{
A comunicação médico - paciente pediátrico - família na perspectiva da criança
}

\author{
Doctor-pediatric patient - family communication, from the child's perspective
}

\author{
Letícia Macedo Gabarra ${ }^{[a]}$, Maria Aparecida Crepaldi ${ }^{[b]}$
}

[a] Doutora em Psicologia pela UFSC (2010), atualmente é docente do curso de Psicologia da Faculdade de Ciências Sociais de Florianópolis (CESUSC), Florianópolis, SC - Brasil, e-mail: leticiagabarra@gmail.com

[b] Doutora em Saúde Mental pela UNICAMP, docente do curso de Graduação e Pós-Graduação em Psicologia da UFSC, membro do Laboratório de Psicologia da Saúde, Família e Comunidade (LABSFAC - UFSC), Florianópolis, SC - Brasil.

\section{Resumo}

Esta pesquisa visou a descrever a comunicação médico - paciente pediátrico - família na perspectiva da criança. Participaram do estudo 15 crianças hospitalizadas com doenças crônicas. Foram realizadas entrevistas semiestruturadas, utilizou-se a análise de conteúdo temático, que resultou em cinco categorias: tipos de comunicação, conteúdos comunicados, comunicação médico - paciente pediátrico - família, comunicação intrafamiliar e fontes de informação. Os tipos de comunicação citados foram a direta e a indireta. Em relação aos conteúdos comunicados, as crianças recordaram dos momentos de menor sofrimento. As crianças referiram que os profissionais conversam mais com os seus pais do que com elas. A comunicação familiar foi indicada como a principal fonte de informação sobre a doença. Desta forma, considera-se que as crianças possuem capacidade de compreender e perceber o que ocorre com o seu corpo; no entanto, os profissionais e a família tendem a omitir informações visando a protegê-las de maiores sofrimentos.

Palavras-chave: Comunicação médico - paciente pediátrico - família. Doença crônica. Psicologia da saúde. Psicologia pediátrica.

\begin{abstract}
The objective of this research was to outline the communication between doctor, pediatric patient and the family from the perspective of the child with chronic disease. Fifteen hospitalized children have participated in it, the included age range being between 5 and 13 years old; Firstly, semi-structured interviews were applied and then the data was analyzed according to the 'thematic content analysis technique'. The analysis resulted in 5 categories: type of communication, content communicated, communication doctor - pediatric patient-family, intra-family communication and sources of information. The children examined showed two types of communication: direct and indirect. In relation to the content of the communication, the children remembered the moments which generated less suffering.
\end{abstract}


All the children said the professionals talked more to their parents, rather than directly to them. Familiar communication was said to be the main source of information about the illness. In this way it was seen that children have the capacity to understand and perceive what happens with their bodies, however professionals and family tend to omit information with the intention of protecting them from greater suffering.

Keywords: Doctor - pediatric patient - family communication. Chronic disease. Public health psychology. Pediatric psychology.

\section{Introduçáo}

\section{Comunicaçáo com a criança sobre a sua doença}

A comunicação médico-paciente exige do profissional uma grande habilidade, que envolve técnica, conhecimento teórico, ética e sensibilidade. Os princípios da confiabilidade e relato da verdade devem estar presentes na comunicação (Garrafa \& Albuquerque, 2001). Os cursos de Medicina demonstram preocupação na formação dos profissionais capacitados em comunicar de forma clara e ética (Perosa \& Ranzani, 2008).

A comunicação em pediatria possui características peculiares comparadas aos pacientes adultos, visto que a criança está em processo de desenvolvimento cognitivo, social e psicológico, além de possuir adultos responsáveis pela sua saúde. As dificuldades na comunicação da equipe de saúde com a criança foram constatadas em diversos estudos (Nova, Vegni \& Moja, 2005; Perosa \& Ranzani, 2008; Tates \& Meeuwesen, 2001).

Tates e Meeuwesen (2001) verificaram nos estudos sobre comunicação médico - paciente pediátrico a não participação da criança na conversa médica. A exclusão da criança na comunicação foi evidenciada em pesquisas internacionais (Hart \& Chesson, 1998; Tates \& Meeuwesen, 2001; Young, Dixon-Woods, Windringde \& Heney, 2003; Nova et al, 2005) e nacionais (Mendonça, 2007; Armelin, Wallau, Sarti \& Pereira, 2005; Oliveira, Oliveira, Gomes \& Gasperin, 2004; Marcon, 2003). Estes estudos identificaram que a comunicação médica, no atendimento pediátrico, ocorre entre o profissional e os pais, principalmente a mãe, enquanto a criança é excluída. As informações sobre a saúde da criança são fornecidas pelos pais e a relação médico - paciente pediátrico restringe-se ao contato afetivo.
Hart e Chesson (1998) hipotetizam que isso pode ocorrer em virtude de dois fatores: alguns profissionais não sabem como abordar a criança verbalmente; outros, apesar de terem interesse no que elas pensam e desejam, tentam protegê-las de informações médicas, para não perturbá-las emocionalmente. A falta de comunicação com pacientes pediátricos, na tentativa de minimizar o sofrimento, pode ser fonte maior de angústias e fantasias (Bessa, 1998).

Lapacó, Herran e Navari (1996) mencionam que alguns médicos consideram desnecessário informar sobre a doença e saber a opinião das crianças, além de avaliarem como prejudicial oferecer informação para esses pacientes, pois consideram que eles podem não querer colaborar com o tratamento. Claffin e Barbarin (1991) salientam que a busca pela proteção omitindo a comunicação sobre a doença com a criança é equivocada, pois é impossível protegê-la totalmente ocultando informações, tendo em vista as evidências de que a criança experiencia em seu corpo a mudança de rotina e o tratamento que precisa percorrer. Assim, estes autores afirmam que a criança sabe que algo está acontecendo com ela.

Além da dificuldade dos profissionais de saúde, notou-se que a família também tem preocupações e dúvidas sobre a comunicação com a criança sobre o adoecimento. Muitos pais que têm filhos com doenças crônicas, como o câncer, relutam em falar com a criança sobre o adoecimento, pois acreditam que assim o filho será poupado do sofrimento e do estigma da doença (Rabuske, 2004). Não falar com o filho sobre sua doença é uma estratégia de proteção utilizada pelos cuidadores contra os efeitos psicossociais que o adoecimento pode acarretar na vida da criança e contra as incertezas que traz à vida familiar (Claflin \& Barbarin, 1991).

Nova et al. (2005) detectaram, em o seu estudo qualitativo, a pouca participação da criança na comunicação durante os atendimentos médicos. 
Porém, as crianças pesquisadas demonstraram ser ativas e tentavam se comunicar com os adultos (pais e médicos) sobre sua experiência subjetiva do adoecimento. A pesquisa evidenciou também que as crianças têm autonomia no seu processo de aprendizagem einteriorizam conhecimentos médicos, sendo capazes de informar espontaneamente, ou quando solicitadas, sobre seu estado de saúde.

Dessa forma, a comunicação efetiva com a criança torna-se imprescindível para a sua compreensão do processo de adoecimento e tratamento. Para isso se consideram necessários novos estudos sobre o processo de comunicação em psicologia pediátrica (Mendonça, 2007; Perosa, Gabarra, Bossolan, Ranzani \& Pereira, 2006; Nova et al., 2005). O objetivo deste artigo é descrever a comunicação médico - paciente pediátrico-família na perspectiva da criança com doença crônica.

\section{Método}

\section{Tipo de pesquisa}

Caracteriza-se por ser uma pesquisa exploratório-descritiva de abordagem qualitativa.

\section{Participantes e local}

A pesquisa foi realizada em unidades de internação de um hospital infantil, cujas crianças eram acometidas por doenças crônicas com diagnóstico recente. Participaram 15 crianças hospitalizadas, 6 do sexo masculino e 9 do feminino, na faixa etária de 5 a 13 anos, dividida em pré-escolares (5 e 6 anos) e escolares (7 a 13 anos). As doenças foram diagnosticadas como: diabetes, dermatomiosite, Doença de Wilson, hepatite autoimune e câncer (leucemias, linfomas, tumor de Burkit). Todas as crianças entrevistadas possuíam acompanhante durante a internação, apenas uma estava acompanhada pelo pai e uma com outro familiar; as demais estavam com as mães. O hospital contava com um Serviço de Psicologia que prestava atendimento às crianças hospitalizadas. Os nomes utilizados na apresentação dos resultados são fictícios, preservando a identidade dos participantes.

\section{Procedimento}

O projeto de pesquisa foi aprovado pelo Comitê de Etica e cumpriu a Resolução 196/96 do Conselho Nacional de Saúde e o Código de Ética Profissional dos Psicólogos. A coleta foi feita em três etapas:

1) Primeira etapa: familiarização, exploração e caracterização preliminar das unidades. Realizou-se a observação participante de campo com o objetivo de familiarização da pesquisadora com o campo pesquisado. Esta etapa teve a duração de dois meses.

2) Segunda etapa: explicou-se sobre o estudo às crianças e acompanhantes e perguntou-se sobre o interesse em participar. Mediante a demonstração de interesse de ambos, o responsável assinou o Termo de Consentimento Livre e Esclarecido. Com todas as crianças, realizou-se rapport antes da coleta de dados, utilizando-se de material lúdico de papel e lápis e brinquedos. Mediante o estabelecimento de vínculo com o participante, realizava-se a entrevista com a criança.

3) Terceira etapa: entrevista aberta com a criança que investigava sobre as seguintes temáticas: a comunicação com a equipe e com a família sobre o adoecimento e tratamento; a compreensão sobre a sua doença e a hospitalização. As perguntas foram sendo suscitadas pelo conteúdo das verbalizações das crianças nos diálogos. As entrevistas eram realizadas apenas com a criança, porém houve interrupções de profissionais da equipe e de familiares. O registro foi feito com o uso de gravador e posteriormente foi transcrito na íntegra.

\section{Análise dos dados}

Os dados foram analisados segundo a técnica de análise do conteúdo proposto por Bardin 
(1977), que se divide didaticamente em três fases: a pré-análise, análise e o tratamento dos resultados e interpretação. A pré-análise pressupõe o contato inicial com o material e a escolha deste, dos quais se realizaram leituras exaustivas. Este processo consiste em conhecer o documento analisado, compreender o texto e permitir se envolver por impressões e identificar conteúdos significativos. $\mathrm{Na}$ fase da análise, os temas foram agrupados e posteriormente houve o tratamento dos dados e sua interpretação.

\section{Resultados}

Os resultados foram agrupados em cinco categorias: 1) Tipos de comunicação; 2) Conteúdos comunicados; 3) Comunicação médico - paciente pediátrico; 4) Comunicação intrafamiliar; 5) Fontes de informação. As categorias serão apresentadas separadamente a seguir. Nas frases das crianças foram utilizados: $\mathrm{P}$, para designar o pesquisador, e $\mathrm{C}$, para se referir às crianças participantes.

\section{Tipos de comunicaçáo}

Nesta categoria foram consideradas duas formas de comunicação: a direta e a indireta. A primeira se caracterizava pelo diálogo do adulto (equipe de saúde ou família) com a criança, e na segunda as crianças "descobriam" seu diagnóstico ao ouvirem a conversa entre os adultos, seja entre os familiares, seja entre a família e a equipe. Esta última foi mais frequente entre os pré-escolares, porém também ocorreram entre os escolares, como pode ser observado nas frases a seguir:

Ele [médico] contou para minha mãe. Eu escutei (Gabriela, 8 anos).

Pesquisadora (P) - E como você ficou sabendo que tava doente?

Criança (C) - Minha mãe me falou.

$P$ - Tua mãe te falou. O que ela te falou?

C-Quer dizer... eu acho que ela não falou nada, mas... é... eu ouvi ela ligando pra minha ambulância, aí... para me trazer para Floripa [...]. Eu sabia porque en ouvi ela falando.

$P$ - Ah. Aí, vocês vieram para cá, e o que você ficou sabendo que você tinha?
C - Que eu tinha voltado a doença assim.

$P$ - Que doença é essa?

$C$ - É leucemia.

$P$ - E esse nome que você me falou, leucemia, quem te falou esse nome?

$C$ - Ah, eu ouvi minha mãe dizendo pra uma amiga dela aí, agora eu vou saber que a minha doença é leucemia (Danilo, 5 anos).

Quanto menor a criança, mais ela parece ser excluída da comunicação da doença. No entanto, elas relataram como são atentas a tudo o que ocorre na sua família, nas conversas dos pais com as pessoas e entre si, tornando essa a sua forma de saber sobre a doença.

\section{Conteúdos comunicados}

Compõem essa categoria os temas considerados positivos e negativos. Os temas positivos referem-se: ao tratamento, à cura ou ao controle da doença, a informações relativas à alta e à melhora dos sintomas. Os temas negativos são compostos por conteúdos que denotam os períodos considerados de crise, como a piora dos sintomas e a revelação do diagnóstico.

As crianças citaram principalmente os conteúdos positivos; essas situações foram lembradas com mais facilidade pelas crianças. Assim, elas pontuaram sobre a comunicação da alta e a melhora dos sintomas: "O médico disse que agora ela [massa - denominação dada pela criança ao seu tumor] desapareceu" (Gabriela, 8 anos).

As crianças citaram que a equipe lhes informou sobre os comportamentos e ações adequadas para o tratamento e para a prevenção do dano: "Ela (médica) falou que tem que tomar suco" (Fernanda, 8 anos).

Os conteúdos negativos, considerados "ruins", foram pouco lembrados: "[o médico] fala bastante coisa. Eu não lembro de nada. Ah, ele [médico] fala quando vai para casa" (Danilo, 5 anos).

A linguagem médica também foi citada como um dificultador na compreensão das informações e pelo distanciamento na relação médico-paciente: "Eu não entendo muito bem assim as palavras dos médicos. Eles dizempalauras estranhas, nomes estranhos" (Nádia, 10 anos). 


\section{Comunicação médico - paciente pediátrico - familia}

Nesta categoria foram incluídos os seguintes conteúdos: quem participa da comunicação sobre a doença; como a criança gostaria que fosse e como ela gostaria de ser informada; os temas que deveriam compor a comunicação e os sujeitos participantes.

As crianças demonstraram ser excluídas das comunicações estabelecidas entre médico e familiares. "Ele [médico] não conversa com a gente. Ele é brabo. Só com a minha mãe [ele conversa]. Ele conversa mais com a minha mãe. Eles [pais e médicos] conversam quando eu estou dormindo (Gabriela, 8 anos).

A exclusão das crianças nas comunicações, principalmente sobre o diagnóstico, ocorreu com maior frequência com as crianças com menos que 10 anos. As crianças maiores de 10 anos relataram conversas com os médicos, como Tiago, que afirmou que a médica lhe comunicou sobre a sua doença, mesmo posteriormente privilegiando a conversa com sua mãe: "Só falou que a doença era câncer no sangue, dai era leucemia, só, dai ela [médica] conversou com a minha mãe" (Tiago, 13 anos).

Algumas crianças souberam identificar diferenças entre as pessoas da equipe médica. Consideraram que existem médicos que conversam e outros que não. Assim, Fernanda disse:

$C$ - Tem uns que não falam [médicos].

$P$ - Tem uns que não falam? Quem que não fala?

$C$ - Tem uma doutora que não fala.

$P$ - Tem uma doutora que não fala?

$\mathrm{C}$ afirma com a cabeça.

$P$ - Por que será que ela não fala?

$C$ - Não sei. Porque ela não sabe (Fernanda, 8 anos).

Fernanda considerou que existem médicos que não sabem conversar com ela ou não sabem sobre a sua doença. A compreensão desta criança talvez esteja permeada pelo vínculo estabelecido com os membros da equipe médica.

As crianças demonstraram interesse em uma comunicação mais próxima com a equipe de saúde, desejavam saber mais sobre a doença e gostariam que os médicos conversassem com elas. Algumas crianças, como Simone e Nádia, souberam dizer o que gostariam que os profissionais lhes falassem, citando o interesse pela etiologia da doença e aspectos da medicação. Mas outras crianças demonstraram o desejo pela comunicação, sem saber citar o que desejariam que fosse conversado. Algumas crianças afirmaram que se os médicos conversassem, elas se sentiriam mais à vontade para lhes perguntar: "Gosto [de saber], mas não pergunto" (Patrícia, 10 anos).

Gabriela descreve o seu comportamento passivo na relação com o médico, mas indica o interesse em se tornar mais ativa. O papel da criança durante os exames ou visitas médicas parece ser passivo, visto que elas não perguntavam para a equipe médica suas dúvidas. Delegavam essa função à mãe, inclusive as crianças maiores: "quem pergunta é a mãe. Porque dai depois ela me diz, eu não sei, tem algumas coisas que eu pergunto, algumas não" (Nádia, 10 anos).

Algumas crianças maiores, como Simone, demonstraram ter uma postura ativa na relação com a equipe médica. No entanto, ela relatou seu desapontamento pela falta de atenção da equipe destinada às suas falas:

Às vezes eu não pergunto, porque eu me irrito. Eu per-
guntei o que era isso aqui [mostra a pele no braço],
o que eu tinha, falaram que era de coçar.. mas eu tenho
desde de pequena, como vai ser de eu coçar? E a mulher
[médica] fez assim, nem olhou em mim, e falou que
era de eu cosar. [...] Eu pergunto, mas não adianta.
Eles [médicos] não resolvem. Eu já perguntei para
ela [médica] um dia, dai agora eu parei de perguntar
(Simone, 13 anos).

Embora as crianças tenham relatado que se sentem excluídas da comunicação médico-família, consideram imprescindível o papel mediador do familiar, que na maioria das vezes é a mãe. Nádia descreveu como deveria ser a comunicação da equipe médica com a criança:

C-Eu acho que eles deveriam contar um pouco, não
também tudo... Eles deveriam contar mais para as
mães e depois as mães iam contando pra gente assim
devagar... Aí a gente vai entendendo, aí a gente entende
mais quando uma mãe fala. Uma mãe explica melhor
do que o médico.
$P$ - E se os médicos falassem?
C - Aí deveria ser assim o médico falando, mas com
calma, assim, devagarzinho. Mas eu acho melhor as
mães falarem (Nádia, 10 anos).

Nas falas de Nádia, percebe-se um desejo da mediação materna e que a comunicação seja processual, ou seja, ela considera que a criança deve saber 
a verdade, mas de forma gradativa e que a notícia seja dada por uma pessoa com que ela tenha vínculo.

As crianças com mais de 10 anos apontaram desejar saber mais sobre a sua medicação e a hospitalização, como a mudança de unidades no hospital e procedimentos realizados. Porém, o desejo por informações é ambivalente, pois envolve os sentimentos do adoecimento:

Não sei se é melhor (Giane, 13 anos, quando questionada se é melhor não saber).

Converso às vezes, não um monte, porque eu não gosto de saber muito de doença. Depois en fico cismando com aquilo. Não falaram, porque tem coisa que eu lembro, algumas coisas que não. E nem é bom cê ficar sabendo o que é que é a doença, essas coisas. [...]. Acho que é melhor eu nem ficar sabendo muita coisa de doença, assim, porque sei lá (Nádia, 10 anos).

A ambiguidade de falar sobre a doença surgiu nas falas das crianças. Ao mesmo tempo em que é bom falar, não o é; assim, é preciso escolher as pessoas com quem se fala.

Elas [crianças na escola] vão ficarperguntando, e eu não gosto que fiquem perguntando as coisas, insistindo nas coisas. É porque dai tem que lembrar e contartudo. Às vezes, às vezes também não, às vezes é ruim ter que contar. Ficar com aquilo ali guardado para gente também não é muito bom (Nádia, 10 anos).

\section{Comunicação intrafamiliar}

Nesta categoria incluem-se os conteúdos relativos à comunicação da criança com os membros de sua família. A comunicação familiar foi citada como a principal fonte de informação. As crianças indicaram a mãe como a informante principal sobre a sua doença, tratamento e hospitalização. As mães são as responsáveis pela nomeação da doença, localização, orientações sobre os comportamentos de autocuidados e alertas sobre as ações de risco que devem ser evitadas; a informação mais lembrada foi a alimentação. O papel da mãe também foi o de transmissora de informações dadas pela equipe, a codificadora e mediadora, a pessoa que simplifica e explica para a criança sobre o universo médico. O pai, a prima e a tia foram apontados, cada um por um participante da pesquisa, como membros da família que também exercem esta função.

É, explicou um pouco, o pouco que ela [mãe] também sabe, ela também não sabe tudo ainda. A mãe fala, né, porque ela entende mais do que eu. Às vezes, eu falo com a mãe, que é ela que é a mãe da gente, ela sabe mais coisa, né? (Nádia, 10 anos).

A minha mãe já falou algumas coisas para mim (Valéria, 13 anos).

Só o pai falou da doença para mim (Danilo, 5 anos). Às vezes sim, se ela [mãe] sabe, ela explica. Ela [mãe] explica o que tem que fazer e não pode faltar [ao tratamento]... Ela [mãe] falou que não pode se bater, se machucar... Se cuidar quando brincar(Tiago, 13 anos).

No entanto, destaca-se que dentro do contexto familiar surgiram dilemas sobre a comunicação da doença. As crianças perceberam a proteção familiar relacionada à não comunicação.

C - Ela (mãe) falou que... eles [pais] não queriam falar [sobre a doença].

$P$ - Quem não queria falar? A mãe, o médico? Quem?

$C$ - A minha mãe, meu pai (Valéria, 13 anos).

C - Tem coisa que ela [mãe] não fala, que eu não posso saber.

$P$ - O que você não pode saber?

$C$ - As coisas que ela não deixa eu saber.

$P$ - Por que será que ela não deixa você saber?

C - Não sei.

$P$ - Não? Epor que ela não deixa?

$C$ - Porque tem coisa que eu não gosto.

P- Então se for uma coisa que você não goste, ela não vai te falar?

$C-\dot{E}$.

P - O que, por exemplo, que você acha que ela não te conta?

C - Uma coisa triste, que...

$P$ - Um coisa triste você acha que ela não ia te contar? $C$ - É (Gabriela, 8 anos).

As crianças percebem quando os pais não querem contar. Gabriela exemplifica que a mãe não conta sobre assuntos tristes. Assim, os segredos em torno da comunicação diagnóstica permeiam algumas famílias, nas quais todos sabem da doença, porém, não falam sobre isso. Patrícia descreveu claramente o "segredo" na sua família e, apesar de todos saberem sobre a doença, não conversam sobre isso. 
C - Mas ela sabe que eu sei.

P - Como ela sabe que você sabe?

$C$ - Porque ela sabe (risos).

$P$ - Mas você falou para ela?

C - Não, mas ela sabe que en sei que ela sabe que ela sabe que eu sei (risos).

$P$ - Mas vocês não conversam disso?

$C$ - Não. Eu não gosto (Patrícia, 10 anos).

As crianças pesquisadas explicitaram que a comunicação familiar envolve também a discussão sobre os saberes, o saber popular e o saber oficial da medicina. Assim, Simone relatou que os detentores do saber sobre a doença são as pessoas especializadas e ligadas ao universo científico. Ela preferia conversar com a tia, pois esta era profissional da área de saúde.

Não, porque lá em casa ninguém sabe, é todo mundo meio leigo assim... Eu pergunto só que se ela [mãe] tiver falando errado para mim, e eu for lá e fizer coisa errada... Dai en prefiro a minha tia, ela deve saber tudo. Não quer dizer que porque ela esteja cursando ela sabe tudo...

\section{Fontes de informaçáo}

Nesta categoria foram incluídos os seguintes informantes: médicos, familiares, nutricionistas, psicólogos, professores e internet.

A nutricionista foi mencionada como informante sobre o tratamento, por causa de todas as restrições alimentares da doença. Entre os profissionais de saúde, o psicólogo foi citado como fonte de informação sobre o adoecimento, o tratamento e os efeitos colaterais da medicação. As crianças com câncer lembraram-se das cartilhas trazidas pelo Serviço de Psicologia como forma de saberem sobre a sua doença. $\mathrm{Na}$ fala de Caio verifica-se o conhecimento da doença por meio da cartilha: "éporque uma tia [psicóloga] me deu um soldadinho, um livrinho de soldadinho, e dai eu vejo e... (Caio, 5 anos).

Henrique levou a cartilha à escola para a professora ler e ensinar para as outras crianças sobre a sua doença, trazendo ao seu microssistema informações advindas do hospital, como multiplicador de informações, uma forma de desmistificar a representação do câncer entre as crianças. A cartilha para algumas crianças foi compreendida como uma forma lúdica de ter informações sobre a doença, podendo compartilhar com outras crianças da família e com amigos da escola.

O livrinho está com a minha professora, dei para ela ver (Henrique, 8 anos).

Eu achei legal a historinha (Patrícia, 10 anos).

A professora da escola foi indicada por Simone como informante sobre a doença, pois esta teve uma doença parecida com a dela, e explicava-lhe sobre o funcionamento corporal, auxiliando na sua compreensão sobre a doença. A clarificação da doença também foi transmitida aos seus colegas da escola, para que estes pudessem compreendê-la e auxiliá-la quando necessário. Esta pré-adolescente apontou a internet como uma possibilidade de se obter informações sobre a doença.

Algumas crianças não conseguiram identificar os seus informantes. Diziam que ninguém havia the falado sobre a doença. Isso ocorreu em geral com as crianças pré-escolares. Pode-se pensar se realmente não lhes foi dito nada, ou se disseram, porém, elas não compreenderam, ou ainda se disseram e elas não suportaram as informações em virtude do impacto emocional.

\section{Discussão}

O tipo de comunicação mais frequente nesta pesquisa foi indireta, confirmando os dados da pesquisa de Young et al. (2003). Esses autores estudaram crianças com câncer e apontaram que primeiramente o diagnóstico foi revelado pelos médicos para os pais, sem a presença do paciente. Porém, nesta pesquisa as crianças estavam presentes no momento do diagnóstico, recebendo a comunicação de forma indireta, conforme relato das crianças entrevistadas e observado pela pesquisadora durante o período da observação participante de campo.

A pesquisa aponta para o fato de as crianças saberem sobre sua doença por meio de falas entre os adultos ou pela percepção facial dos adultos, demonstrando que algo não está bem. Essa percepção infantil foi identificada por Castro e Piccinini (2002), que consideram que a criança percebe os fatos que o adulto quer esconder, e que os adultos têm dificuldade em apreender esses sinais da criança ou talvez 
não queiram aceitar o adoecimento. Para favorecer a comunicação diagnóstica entre equipe e a criança, Giuseppe et al. (2000) propõe que os profissionais precisam demonstrar confiança, respeito e envolvê-la ativamente nesta situação.

Cabrera (1995) considera que a comunicação efetiva da tríade pode auxiliar a criança e a família, e principalmente proporcionar a autonomia da criança sobre o seu próprio cuidado. DiMatteo (2004) avalia que a comunicação sobre o tratamento com o paciente pediátrico e a família é fundamental na adesão aos regimes terapêuticos, essenciais nas doenças crônicas. Nesse sentido, a criança precisa compreender os aspectos do tratamento e suas repercussões positivas e negativas em sua vida, possibilitando uma corresponsabilização da criança, da família e da equipe no processo de tratamento.

Pode-se hipotetizar que as crianças pesquisadas "preferem" ouvir as más noticias da mãe e não do médico, e que por esta razão só "ouvem" quando ele diz o que é considerado bom ouvir (aqui é que penso que talvez elas possam "não ter ouvido" o diagnóstico ou talvez os médicos, sem saber da reação da família, transmitissem o diagnóstico longe das crianças), como a alta e a melhora da doença. Talvez a criança escute o que possui condições emocionais para assimilar naquele momento. Para as crianças menores, como Danilo, a comunicação da saída do hospital possui um grande destaque durante o processo de hospitalização. As crianças recordam com clareza essa informação, enquanto outras são esquecidas. Talvez isso possa indicar a dificuldade em enfrentar e lidar com a comunicação de más notícias, como um diagnóstico desfavorável. Claflin e Barbarin (1991) argumentam que a comunicação de diagnóstico pode ser tão emocionalmente esmagadora que há uma tendência em negar ou reprimir essa informação.

Além dos aspectos emocionais da comunicação, deve-se considerar o linguajar médico como um dificultador desse processo, pois os termos técnicos são incompreensíveis para o universo infantil. O médico Botsaris (2001, p. 108) faz uma crítica a essa linguagem técnica, chamando-a de "dialeto que só médicos compreendem" ou "medicinês". Este autor acredita que esse fenômeno seja uma forma de proteção desses profissionais, ao utilizar um código secreto.
A partir das falas das crianças pesquisadas, observou-se que as comunicações ocorriam entre os adultos, isto é, entre os profissionais e os familiares, evidenciando que as crianças não eram incluídas nessas conversas. Esses dados foram ao encontro da literatura da área (Hart \& Chesson, 1998; Tates \& Meeuwesen, 2001; Marcon, 2003; Mendonça, 2007).

Poré, quanto maior a idade, elas passavam a ser incluídas. Nesse sentido, as crianças escolares participaram das comunicações com os médicos e com os familiares. Autores apontam a relação entre comunicação da equipe com a criança e o aumento de sua idade: quanto mais velha a criança, mais lhe incluem nas comunicações (Claflin \& Barbarin, 1991, Delella \& Araújo, 2002).

O papel dos pais na comunicação foi evidenciado em várias falas dos participantes da pesquisa, indicando o papel de intermediários das informações médica para os filhos. Os pais clarificam ou reiteram as informações transmitidas, de forma que esclarecem dados sobre a doença à criança, para que esta possa assimilar o que o profissional de saúde lhe disse.

Dessa forma, acredita-se que o vínculo pode proporcionar uma melhor comunicação e compreensão das informações. Cabrera (1995) considera que a comunicação precisa envolver a escuta sobre os temores e dúvidas da criança, para que, assim, o processo de comunicação seja facilitado.

As mães ocuparam papel de destaque como transmissora principal das fontes de informação dos filhos, tanto sobre a doença quanto sobre a hospitalização. Esse mesmo resultado foi encontrado na pesquisa de Veríssimo (1991) com crianças hospitalizadas. No entanto, pode-se questionar se as mães são colocadas nessa função de informante por terem mais oportunidade de saberem sobre a doença, visto que, na maioria dos casos, acompanham mais a hospitalização e o tratamento dos filhos, em comparação com os pais ou outros familiares.

Outra fonte de informação bastante lembrada pelas crianças da pesquisa foi as cartilhas sobre a doença. Costa Jr, Coutinho, Couri e Resende (2001) salientam que o uso de cartilhas informativas constitui uma forma eficiente de interação entre a equipe de saúde e os usuários do serviço, pois eles acreditam que, além de fornecer informações sobre o funcionamento do serviço, estas podem esclarecer aspectos técnicos das doenças. 


\section{Consideraçóes finais}

A família mostrou-se fundamental no processo da comunicação diagnóstica infantil, auxiliando a criança a compreender e aderir ao tratamento. As mães foram apontadas como a principal informante sobre a doença e o tratamento. As crianças as escolheram para compartilhar as dúvidas e ansiedades. No entanto, algumas crianças mostraram a dificuldade que os pais apresentam em escutar os seus medos ou em aceitar ter filhos com doenças crônicas. E, apesar de alguns pais tentarem esconder seu sofrimento e suas inquietações, as crianças identificam o que se passa ao seu redor, o que lhes é dito e principalmente o não dito.

As crianças menores disseram ter descoberto a sua doença de forma indireta; em geral, escutaram alguma conversa da mãe com o médico ou com alguma pessoa próxima. As maiores relataram a comunicação com a equipe de saúde. No entanto, as informações mais lembradas são as que possuem relação com a melhora, a cura da doença ou a alta hospitalar. E as informações sobre pioras da doença, transferência de unidades, como a UTI, em geral são esquecidas ou são lembradas de forma confusa. Pode se hipotetizar que isso ocorra graças aos estados emocionais, como medo, insegurança sobre a situação, relacionados com o adoecimento.

Assim, a forma como cada criança lidou emocionalmente com a doença, com a hospitalização, foi determinante para a sua compreensão naquele momento. Os estados emocionais permearam todas as entrevistas, entrar em contato com os sentimentos mostrou-se doloroso. A ambivalência da informação foi exposta pelas crianças, que trouxeram os seus sentimentos. Houve momentos em que algumas delas explicitaram o desejo de saber sobre o seu adoecimento e falar sobre esse tema; outros não queriam que lhes contassem ou conversassem sobre a sua doença. Assim, foi preciso respeitar o momento de cada criança, deixando-as livre para se expressar na quantidade que suportava e também da forma que lhe era possível.

A partir dos resultados apresentados, considera-se que os escolares tenham mais condições de compreender sobre o adoecimento do que os pré-escolares, havendo um desinvestimento na comunicação dos profissionais com estas crianças. Acredita-se que a equipe de saúde precisa aprender sobre psicologia do desenvolvimento para se comunicar com as crianças, informando-as sobre a doença e respondendo às suas dúvidas, promovendo boa interação médico-paciente-família. Porém, sabe-se que poucos são os cursos de graduação na área da saúde que preparam os futuros profissionais para esta atividade.

Cursos, durante a graduação e também posteriormente, sobre a relação com a criança e sua família, que incluam a comunicação da tríade, precisam ser criados para a capacitação desses profissionais, para que estejam preparados para identificar a forma de comunicação da criança e lidar com o conteúdo expresso. Assim, perceber outras formas de comunicação, além da linguagem verbal e direta, torna-se fundamental para lidar com esse tipo de pacientes. A preocupação dos profissionais de saúde deve focalizar o cuidado global das pessoas doentes e suas famílias, englobando seus aspectos emocionais e cognitivos.

\section{Referências}

Armelin, C. B., Wallau, R. A., Sarti, C. A., \& Pereira, S. R. (2005). A comunicação entre profissionais de pediatria e a criança hospitalizada. Revista Brasileira de Crescimento e Desenvolvimento Humano, 15(2), 45-54.

Bardin,L. (1977).Análise de conteúdo. Lisboa: Edições 70.

Bessa, L. C. L. (1998). Câncer infantil: Um diagnóstico difícil de ser informado. Pediatria Moderna, 34(5), 258-263.

Botsaris, A. (2001). Sem anestesia: O desabafo de um médico. Os bastidores de uma medicina cada vez mais distante e cruel. Rio de Janeiro: Objetiva.

Cabrera, F. R. (1995). Autonomía limitada em la relación médico paciente. Revista Chilena Pediatria, 66(2), 81-82.

Castro, E. K., \& Piccinini, C. A. (2002). Implicações da doença orgânica crônica na infância para as relações familiares: algumas questões teóricas. Psicologia: Reflexão e Crítica, 15(3), 625-635.

Claflin, C. J., \& Barbarin, O. A. (1991). Does "telling" less protect more? Relationship among age, information disclosure, and what children with cancer see and feel. Journal of Pediatric Psychology, 16(2), 169-191. 
Costa Jr, A. L., Coutinho, S. M. G., Couri, M. L., \& Resende, R. R. (2001). O uso de manuais educativos em saúde pediátrica: Um exemplo de hemofilia. Pediatria Moderna, 37(5), 190-195.

Delella, L. A., \& Araújo, T. C. C. F. (2002). Câncerna infância: Uma investigação sobre a avaliação de desordem de estresse pós-traumático parental e a experiência da sobrevivência. Psicologia Argumento, 20(31), 42-48.

DiMatteo, M. R. (2004). The role of effective communication with children and their families in fostering adherence to pediatric regimens. Patient Education and Counseling, 45(3), 339-344.

Garrafa, V., \& Albuquerque, M. C. (2001). Enfoque bioético de la comunicación en la relación médico-paciente en las unidades de terapia intensiva pediátricas. Acta Bioethica, 7(2), 355-367.

Giuseppe, M., Chesler, M. A., Jankovic, M., Ablin, A.R., Arush, M. W. B., Breatnach, F., et al. (2000). Orientações sobre a comunicação do diagnóstico. In M. Giuseppe \& J. Spinetta, (Org.). Orientações psicossociais em oncologia pediátrica (pp. 25-38). (Luciana Françoso e Elizabette do Valle Trad). São Paulo: ComitêPsicossocial da Sociedade Internacional de Oncologia Pediátrica - SIOP.

Hart, C., \& Chesson, R. (1998) Children as consumers. British Medical Journal, 316, 1600-1603.

Lapacó, M., Herran, M., \& Navari, C. (1996). El manejo de la información en el paciente pediátrico. Arch Argent Pediatr, 94(2), 111-113.

Marcon, C. (2003). A consulta pediátrica e os aspectos comunicacionais entre o médico residente, a criança e sua família. Dissertação de Mestrado em Psicologia da Universidade Federal de Santa Catarina, Florianópolis.

Mendonça, M. B. (2007). Análise do processo de comunicação entre médico, paciente e acompanhante em onco-hematologia pediátrica. Dissertação de Mestrado em Psicologia da Universidade de Brasília, Brasília.

Nova, N., Vegni, E., \& Moja, E. A. (2005). The physicianpatient-parentcommunication: A qualitative perspective on the child's contribution. Patient Education and Counseling, 58(3), 327-333.
Oliveira, V.Z., Oliveira, M.Z., Gomes, W. B., \& Gasperin, C. (2004). Comunicação do diagnóstico: Implicações no tratamento de adolescentes doentes crônicos. Psicologia em Estudo, 9(1), 9-17.

Perosa, G. B., \& Gabarra, L. M. (2004). Explicações de crianças internadas sobre a causa das doenças: Implicações para a comunicação profissional de saúde-paciente. Interface: Comunicação, Saúde e Educação, 8(14), 135-148.

Perosa, G. B., Gabarra, L. M., Bossolan, R. B., Ranzani, P. M., \& Pereira, V. M. (2006). Aspectos psicológicos na comunicação médico-paciente no setting pediátrico. In: M. A. Crepaldi, B. M. Linhares, \& G. B. Perosa (Org.). Temas em psicologia pediátrica (pp. 13-55). São Paulo: Casa do Psicólogo.

Perosa, G. B., \& Ranzani, P. M. (2008). Capacitação dos médicos para enfrentar situações difíceis: Comunicar más notícias às crianças. Revista Brasileira de Educação Médica, 32(3), 468-473.

Rabuske, M. M. (2004). O processo comunicativo em familias com crianças e adolescentes doentes crônicos. Dissertação Mestrado em Psicologia, Universidade Federal de Santa Catarina, Florianópolis.

Tates, K., \& Meeuweesen, L. (2001). Doctor-parent-child communication. A (re)view of the literature. Social Science and Medicine, 52(6), 839-851.

Veríssimo, M. L. O. R. (1991). A experiência de hospitalização explicada pela própria criança. Revista da Escola de Enfermagem da USP, 25(2), 153-168.

Young, B., Dixon-Woods, M., Windringde, K. C., \& Heney, D. (2003). Managing communication with young people who have a potentially life threatening chronic illness: Qualitative study of patients and parents. BMJ, 326(7384), 305-309.

Recebido: 26/04/2010

Received: 04/26/2010

Aprovado: 30/06/2010

Approved: 06/30/2010 